\title{
PERANCANGAN DAN ANALISIS ENTERPRISE ARCHITECTURE PT. XYZ PADA DOMAIN ARSITEKTUR BISNIS DENGAN MENGGUNAKAN FRAMEWORK TOGAF ADM
}

\author{
${ }^{1}$ Ratih Cintya Lestari, ${ }^{2}$ Mochamad Teguh Kurniawan ${ }^{3}$ Rahmat Mulyana \\ ${ }^{1,2,3}$ Program Studi Sistem Informasi, Fakultas Rekayasa Industri, Universitas Telkom \\ ${ }^{1}$ ratihcintya@students.telkomuniversity.ac.id, ${ }^{2}$ teguhkurniawan@telkomuniversity.ac.id, ${ }^{3}$ rahmatmoelyana@telkomuniversity.ac.id
}

\begin{abstract}
Abstrak-Kebijakan pemerintah terkait Badan Penyelenggara Jaminan Sosial (BPJS) menjadi tantangan baru bagi praktisi kesehatan yang ada di Indonesia. Organisasi layanan kesehatan harus mempunyai rancangan strategis baru yang dapat menyelaraskan strategi bisnis dan strategi teknologi informasi sesuai dengan kebutuhan BPJS. Metode yang dapat digunakan untuk menyelarasakan strategi bisnis dan strategi teknologi informasi ialah arsitektur enterprise. The Open Group Architecture Framework (TOGAF) merupakan salah satu framework yang dapat menjadi pedoman pembuatan arsitektur enterprise. Melalui TOGAF, dapat dihasilkan blueprint arsitektur bisnis, blueprint arsitektur sistem informasi dan blueprint arsitektur teknologi sebagai rancangan roadmap kerjasama antara organisasi kesehatan (yang dalam penelitian ini mengambil studi kasus PT. XYZ) dengan BPJS.
\end{abstract}

Kata kunci: arsitektur enterprise, blueprint, arsitektur bisnis, TOGAF, BPJS.

\section{PENDAHULUAN}

Kebijakan Sistem Jaminan Sosial Nasional (SJSN) [1] terkait Badan Penyelenggara Jaminan Sosial (BPJS) memberikan dampak untuk semua perusahaan di seluruh Indonesia, khususnya layanan kesehatan. Praktisi layanan kesehatan di Indonesia saat ini sedang melakukan proses pembelajaran dan mencari ilmu untuk mempersiapkan diri bergabung dengan BPJS [2].

Seiring dengan bergabungnya BPJS dengan layanan kesehatan, maka layanan kesehatan tersebut akan mengalami banyak perubahan untuk menyesuaikan diri dengan kebijakankebijakan yang telah ditentukan oleh BPJS. Perubahan ini mencakup perubahan bisnis dan perubahan infrastruktur (sistem informasi dan teknologi). Salah satu layanan kesehatan yang sedang mempersiapkan diri ialah PT. XYZ.

Pada awalnya, PT. XYZ dibangun hanya unuk melayani kesehatan pegawai Telkom dan keluarganya, serta pensiunan Telkom dan keluarganya. Namun dengan diterbitkannya kebijakan SJSN yang baru terkait BPJS, klinik-klinik yang dimiliki oleh PT. XYZ diharuskan dapat melayani peserta BPJS. Hal ini yang menjadi tantangan bagi PT. XYZ agar dapat melakukan perubahan dan menghindari adanya masalah besar yang terjadi di kemudian hari. Perubahan tersebut membutuhkan perencanaan sistem secara menyeluruh dari berbagai aspek. Perencanaan sistem secara menyeluruh tersebut dapat dilakukan dengan metode arsitektur enterprise (enterprise architecture).

Penelitian ini bertujuan merancang dan menganalisis kebutuhan-kebutuhan, khususnya dari segi bisnis, yang nantinya dibutuhkan oleh PT. XYZ saat bekerja sama dengan BPJS. Berdasarkan kebutuhan tersebut, maka akan dibuat rancangan blueprint arsitektur bisnis yang dapat dijadikan pedoman dalam implementasi kebijakan BPJS.

\section{METODOLOGI PENELITIAN}

A. Kerangka Kerja

TOGAF Architecture Development Method (ADM) yang dikeluarkan oleh The Open Group pada tahun 2009, TOGAF menyediakan proses-proses untuk membangun arsitektur yang mencakup pembangunan framework arsitektur, pengembangan konten arsitektur, transisi, and pengaturan/pengendalian terhadap realisasi arsitektur. Semua aktivitas tersebut dilakukan dalam sebuah siklus yang berulang dan berkelanjutan, yang memungkinkan organisasi untuk melakukan transformasi enterprise yang terkontrol sebagai respon atas tujuan dan peluang bisnis [3].

Gambar 1 menunjukkan hubungan antar fase-fase yang ada dalam TOGAF ADM. Fase fase tersebutdiantaranya:

a. Preliminary Phase

b. Phase A: Architecture Vision

c. Phase B: Business Architecture

d. Phase C: Information System Architecture

e. Phase D: Technology Architecture

f. Phase E: Opportunities \& Solutions

g. Phase F: Migration Planning

h. Phase G: Implementation Governance

i. $\quad$ Phase H: Architecture Change Management

j. $\quad$ Requirements Management 


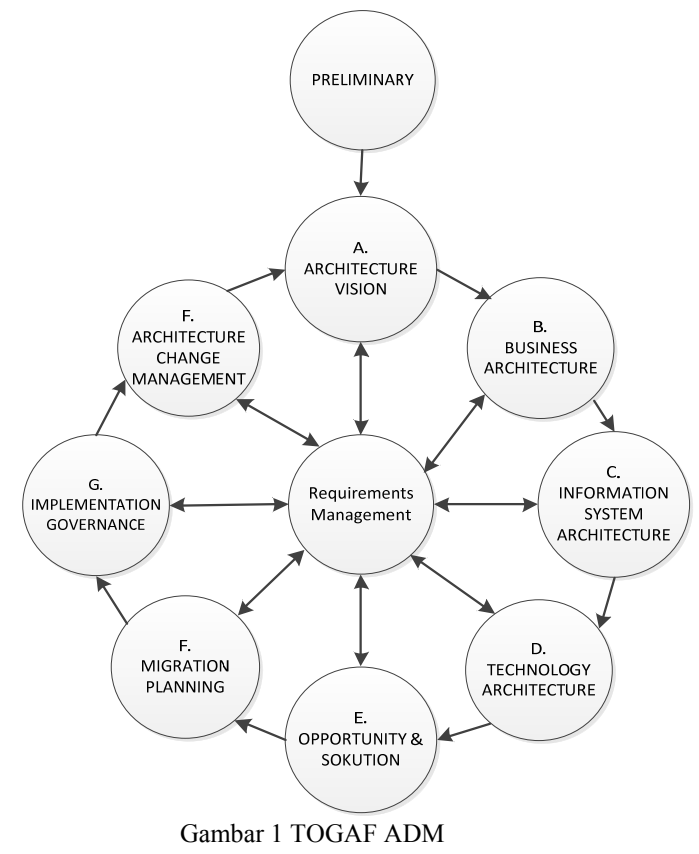

Tahap awal dari penelitian ini ialah mengidentifikasi masalah dan menentukan batasan masalah penelitian. Hal tersebut dapat ditentukan melalui studi literatur dan studi lapangan yang telah dilakukan. Kemudian dilakukan pengidentifikasian prinsip arsitektur dari PT. XYZ. Prinsip ini terdiri dari prinsip bisnis, prinsip data, prinsip aplikasi dan prinsip teknologi. Setelah prinsip-prinsip arsitektur PT. XYZ teridentifikasi, maka yang dilakukan selanjutnya ialah mengidentifikasi visi misi perusahaan, stakeholder dan key concern untuk dapat dituangkan ke dalam visi arsitektur. Visi arsitektur dapat dibuat setelah semua data yang diidentifikasi divalidasi oleh PT. XYZ.

Setelah pembuatan visi arsitektur, dapat diidentifikai kebutuhan-kebutuhan yang diperlukan didalam setiap arsitektur (bisnis, sistem informasi, dan teknologi). Berdasarkan kebutuhan yang telah diidentifikasi sebelumnya, lalu ditetapkan artefak-artefak (katalog, matriks, diagram) yang akan dibuat. Lalu dibuatlah arsitektur bisnis PT. XYZ saat ini dan arsitektur bisnis PT. XYZ usulan.

Berdasarkan pembuatan arsitektur bisnis PT. XYZ saat ini dan arsitektur bisnis PT. XYZ usulan, dilakukan analisis kesenjangan untuk mengetahui perbedaan dari usulan yang telah dirancang. Lalu dilakukan kembali validasi dari rancangan arsitektur bisnis usulan dan analisis kesenjangan ke pihak PT. XYZ. Setelah pihak PT. XYZ memberikan validasi, maka tahap pelaporan berupa blueprint arsitektur bisnis telah dapat dibuat, dan penarikan kesimpulan dan saran pun dapat dilakukan.

\section{HASIL DAN PEMBAHASAN}

PT. XYZ merupakan layanan kesehatan yang diperuntukan bagi karyawan Telkom dan keluarganya, serta pensiunan Telkom dan keluarganya. Saat ini PT. XYZ mempunyai total peserta 160.000 jiwa yang berasal dari 8 perusahaan besar, diantaranya PT. Telkom, PT. Graha Sarana Duta (GSD), PT. Sigma, PT. Telkom Indonesia Internasional (TII), PT. Patrakom, PT. Daya Mitra, PT. Dana Pensiun (Dapen) [4].

Dengan visi menjadi organisasi pengelola dana yang mandiri dan terpercaya untuk memlihara kesehatan karyawan dan keluarga serta pensiunan dan keluarga Telkom, maka PT. XYZ mulai merancang rencana-rencana untuk mewujudkan visi tersebut. Salah satunya ialah dengan menargetkan kemandirian PT. XYZ pada tahun 2016, seperti yang dituangkan dalam rencana jangka panjang PT. XYZ 20122016 [4].

Saat ini, PT. XYZ telah memiliki delapan area sebagai salah satu langkah mewujudkan visi melayani kesehatan peserta PT. XYZ. Area-area tersebut diataranya Area I Sumatera, Area II Jakarta, Area III Jawa Barat, Area IV Jawa Tengah, Area V Jawa Timur, Area VI Kalimantan, dan Area VII Kepulauan. Selain itu, PT. XYZ sendiri telah memiliki 15 klinik yang tersebar di berbagai kota [4].

Dengan menggunakan value chain porter [5], aktivitasaktivitas kunci maupun aktivitas -aktivitas pendukung serta tujuan utama dari PT. XYZ. Berikut merupakan value chain dari PT. XYZ:

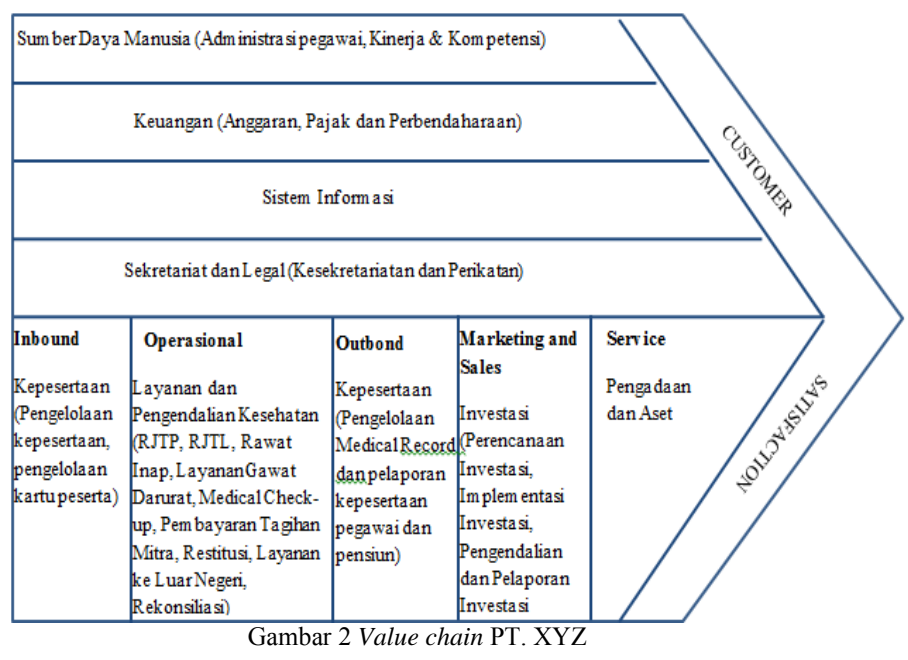

Gambar 2 menujukkan value chain PT. XYZ saat ini. Berdasarkan value chain pada Gambar 4, dapat diketahui bahwa PT. XYZ memiliki aktivitas-aktivitas utama diantaranya kepesertaan, layanan dan pengendalian kesehatan, kepesertaan, investasi, serta pengadaan dan aset. Selain itu, terdapat juga aktivitas-aktivitas pendukung seperti manajemen sumber daya manusia, manajemen keuangan, manajemen sistem informasi, serta sekretariat dan legal.

Gambar 3 menunjukkan business footprint diagram dari PT. XYZ saat ini berdasarkan pada rencana jangka panjang PT. XYZ tahun 2012-2016. Business footprint diagram [6] merupakan diagram yang digunakan untuk menggambarkan hubungan antara pendorong, tujuan, sasaran saling berkaitan. Melalui business footprint diagram, dapat terlihat apa saja sasaran yang berhubungan dengan sebuah tujuan. 
Menghadapi perubahan kebijakan yang didasari oleh BPJS, PT. XYZ melakukan beberapa perubahan secara bertahap. Perubahan - perubahan tersebut membawa dampak terhadap proses bisnis umum yang ada di PT. XYZ.

Gambar 4 menunjukkan proses bisnis umum PT. XYZ setelah bekerjasama dengan BPJS Kesehatan. Pada awalnya, PT. XYZ hanya bekerja sama dengan pihak eksternal seperti vendor, mitra, dan HR perusahaan Telkom. Namun, dengan munculnya kebijakan pemerintah terkait BPJS Kesehatan, maka PT. XYZ diharuskan memberikan pelayanan kepada peserta BPJS Kesehatan dan mendaftarkan peserta PT. XYZ sebagai peserta BPJS Kesehatan.

Saat ini PT. XYZ telah mendaftarkan seluruh pesertanya yang berjumlah 160.000 jiwa sebagai peserta BPJS Kesehatan. PT. XYZ yang sebelumnya telah memiliki proses bisnis terkait pendaftaran peserta dan perubahan data, lalu melakukan perubahan proses bisnis sebagai pedoman pengajuan peserta baru dan perubahan data peserta baru agar dapat langsung terkoordinasi dengan BPJS.
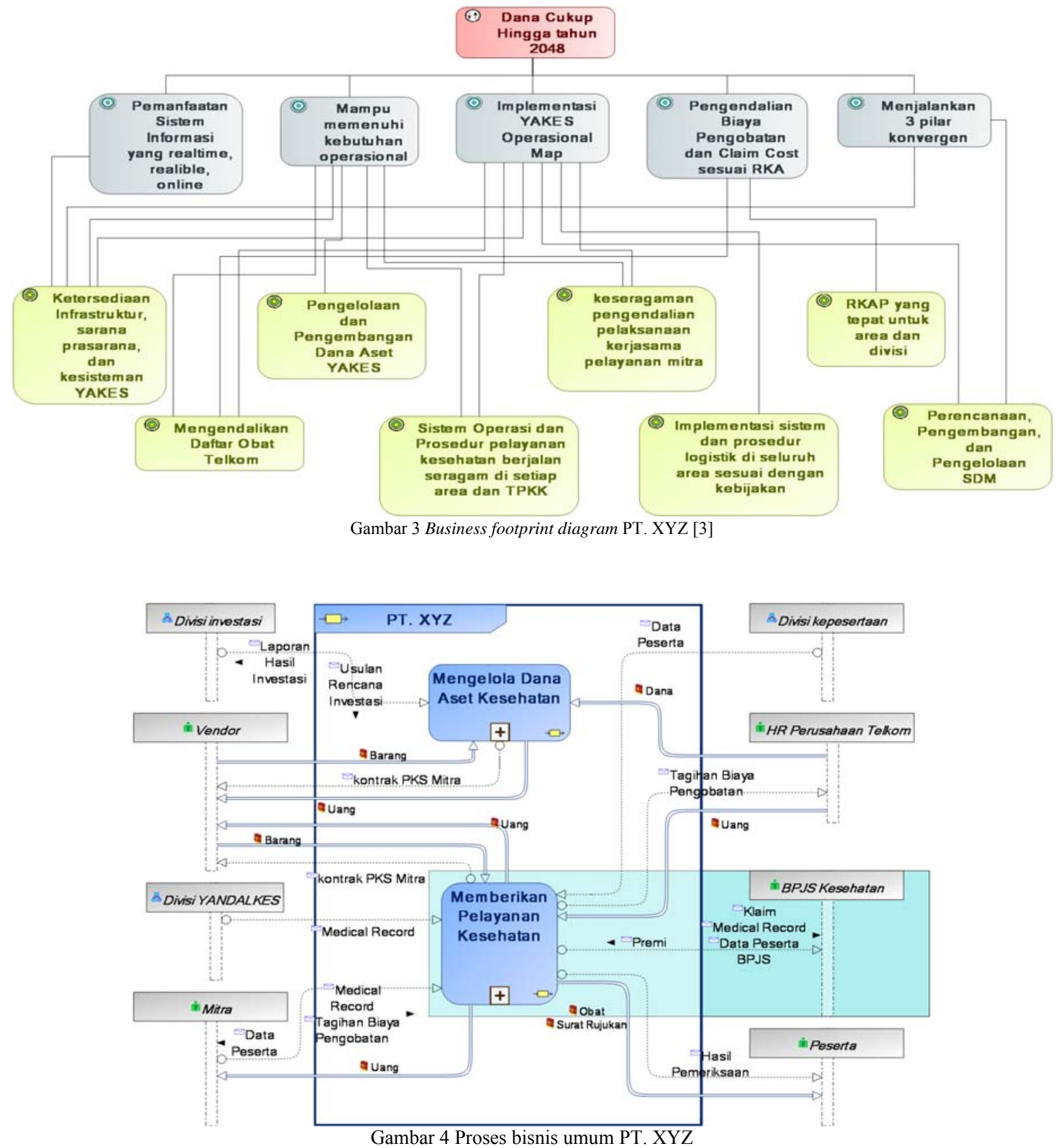
Gambar 5 menunjukkan proses bisnis usulan pengajuan menjadi peserta baru. Perubahan proses bisnis ditandai dengan perbedaan area seperti yang telah digamabrkan. Penambahan proses bisnis ini digunakan untuk mempermudah administrasi dan sebagai standar administrasi yang digunakan apabila PT. $\mathrm{XYZ}$ ingin menambahkan peserta baru. Penambahan aktivitas yang dilakukan diantaranya pelaporan penambahan data peserta baru ke BPJS, penerimaan kartu BPJS dan pemberian kartu BPJS ke HRD Perusahaan atau Manajer Area.

Gambar 6 menunjukkan proses bisnis perubahan data usulan. Area yang berwarna biru menunjukkan penambahan aktivitas-aktivitas untuk menangani perubahan data agar mempermudah dan menjadi standar apabila peserta akan melakukan perubahan data. Aktivitas yang ditambahkan dalam proses bisnis perubahan data diantaranya pelaporan dan penyerahan permohonan perubahan data, sehingga nantinya didapat informasi terkait perubahan data yang nantinya akan diinformasikan ke peserta yang bersangkutan.

Terhitung sejak tanggal 1 April 2015, peserta PT. XYZ telah dapat menikmati layanan yang diberikan oleh BPJS. Tagihan premi seluruh peserta PT. XYZ dibebankan kepada PT. XYZ dengan besar Rp. 8.800.000.000 per bulan untuk seluruh peserta.

Tabel I menunjukkan perubahan hak kelas yang terjadi setelah PT. XYZ mendaftarkan peserta PT. XYZ sebagai peserta BPJS. Konversi tersebut dilakukan untuk mempertahankan mutu pelayanan oleh PT. XYZ untuk peserta PT. XYZ.

TABEL I

KONVERSI HAK KELAS UNTUK RAWAT INAP

\begin{tabular}{|l|l|l|}
\hline Ben & $\begin{array}{l}\text { Layanan } \\
\text { PT. XYZ } \\
\text { sebelumnya }\end{array}$ & $\begin{array}{l}\text { Layanan PT. XYZ setelah } \\
\text { bekerjasama dengan BPJS }\end{array}$ \\
\hline Ben 1 dan Ben 2 & Kelas VIP & $\begin{array}{l}\text { VIP melalui perlakuan Cost } \\
\text { Of Benefit, dengan sisa } \\
\text { pembayarannya dibayarkan } \\
\text { oleh PT. XYZ }\end{array}$ \\
\hline Ben 3 dan Ben 4 & Kelas 1 & Kelas 1 \\
\hline $\begin{array}{l}\text { Ben 5, Ben 6, } \\
\text { dan Ben 7 }\end{array}$ & Kelas 2 & Kelas 1 \\
\hline
\end{tabular}

Langkah yang dilakukan oleh PT. XYZ selanjutnya ialah mempelajari kebijakan yang dikeluarkan BPJS terkait administrasi klaim dan biaya pengobatan. BPJS memberlakukan biaya kesehatan semesta yang digunakan sebagai dasar biaya pengobatan dan klaim BPJS. Biaya kesehatan semesta yang dimaksud, berpedoman pada tarif INA CBG's. Hal tersebut dilakukan untuk mengantisipasi kerugian yang ditanggung oleh PT. XYZ saat melayani peserta BPJS Kesehatan.
Setelah mempelajari semua administrasi klaim dan kebijakan pengobatan, kemudian disusunlah proses bisnis proses bisnis baru sebagai pedoman memberikan pelayan kesehatan untuk peserta BPJS.

Gambar 7 menunjukkan penambahan proses bisnis baru untuk PT. XYZ terkait rawat jalan. Sebagai salah satu organisasi layanan kesehatan, PT. XYZ diharuskan turut andil sebagai salah satu penyedia layanan BPJS. PT. XYZ yang terdaftar sebagai salah satu faslitas kesehatan tingkat pertama harus bisa menangani pasien BPJS yang ingin melakukan rawat jalan di PT. XYZ, oleh karena itu dibuatlah proses bisnis untuk menangani rawat jalan di fasilitas kesehatan tingkat pertama untuk peserta BPJS. Pembuatan proses bisnis ini dilakukan untuk menyesuaikan sistem administrasi PT. XYZ dengan BPJS Kesehatan.

Gambar 8 menunjukkan proses bisnis usulan pelayanan tingkat lanjutan untuk peserta BPJS Kesehatan. Proses binis ini diperlukan karena PT. XYZ diharuskan memberikan layanan tingkat lanjutan untuk peserta BPJS sesuai dengan ketentuan yang telah diberlakukan oleh BPJS. Proses bisnis ini dibutuhkan untuk menyesuaikan prosedur pelayanan BPJS dengan PT. XYZ.

Gambar 9 menunjukkan proses bisnis usulan pelayanan rawat inap untuk peserta BPJS Kesehatan. Selain pelayanan rawat jalan dan pelayanan tingkat lanjutan, PT. XYZ juga membuat proses bisnis pelayanan rawat inap untuk peserta BPJS Kesehatan yang telah disesuaikan dengan tata cara yang ditentukan oleh BPJS. Pembuatan proses bisnis dengan cara menyesuaikan dengan ketentuan BPJS ini dilakukan agar nantinya PT. XYZ dapat menagih klaim sesuai dengan pengeluaran yang telah dikeluarkan.

Setelah semua proses bisnis untuk melayani peserta BPJS Kesehatan telah dibuat. Lalu PT. XYZ membuat proses bisnis sebagai pedoman mengajukan klaim ke BPJS Kesehatan. Berikut merupakan proses bisnis pengajuan klaim pengobatan ke BPJS Kesehatan.

Gambar 10 menunjukkan proses bisnis penagihan klaim. Pembuatan proses bisnis ini dilakukan sebagai standar penagihan klaim setiap bulan yang dilakukan PT. XYZ ke BPJS. Penagihan klaim dilakukan dengan mengumpulkan seluruh daftar tagihan peserta BPJS yang melakukan pengobatan di PT. XYZ, lalu meminta klaim terhadap keseluruhan biaya pengobatan tersebut.

Langkah selanjutnya yang akan dilakukan ialah integrasi sistem yang berjalan di PT. XYZ dan BPJS Kesehatan, serta teknologi pendukung agar integrasi dapat berjalan dengan baik. 

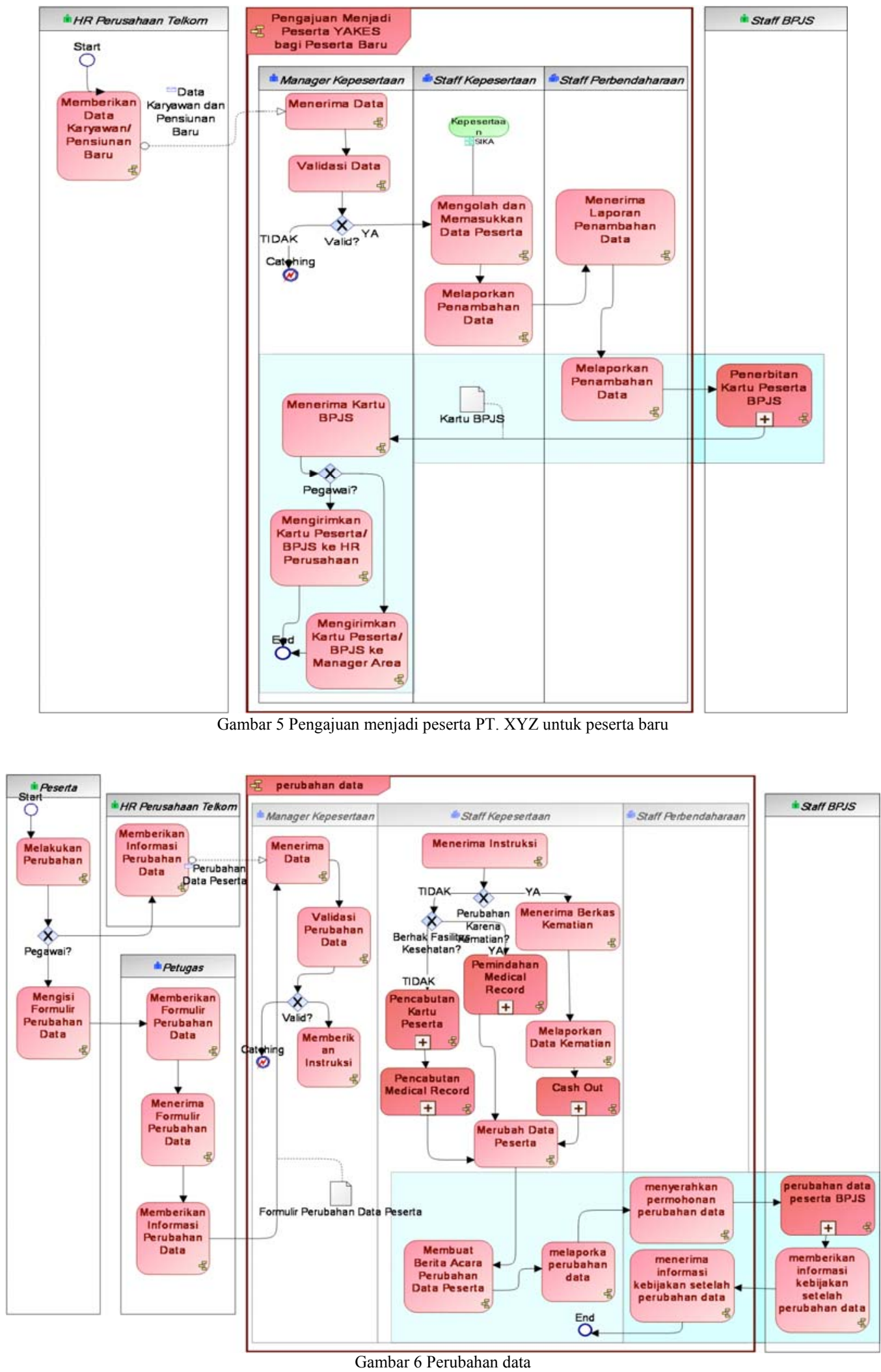


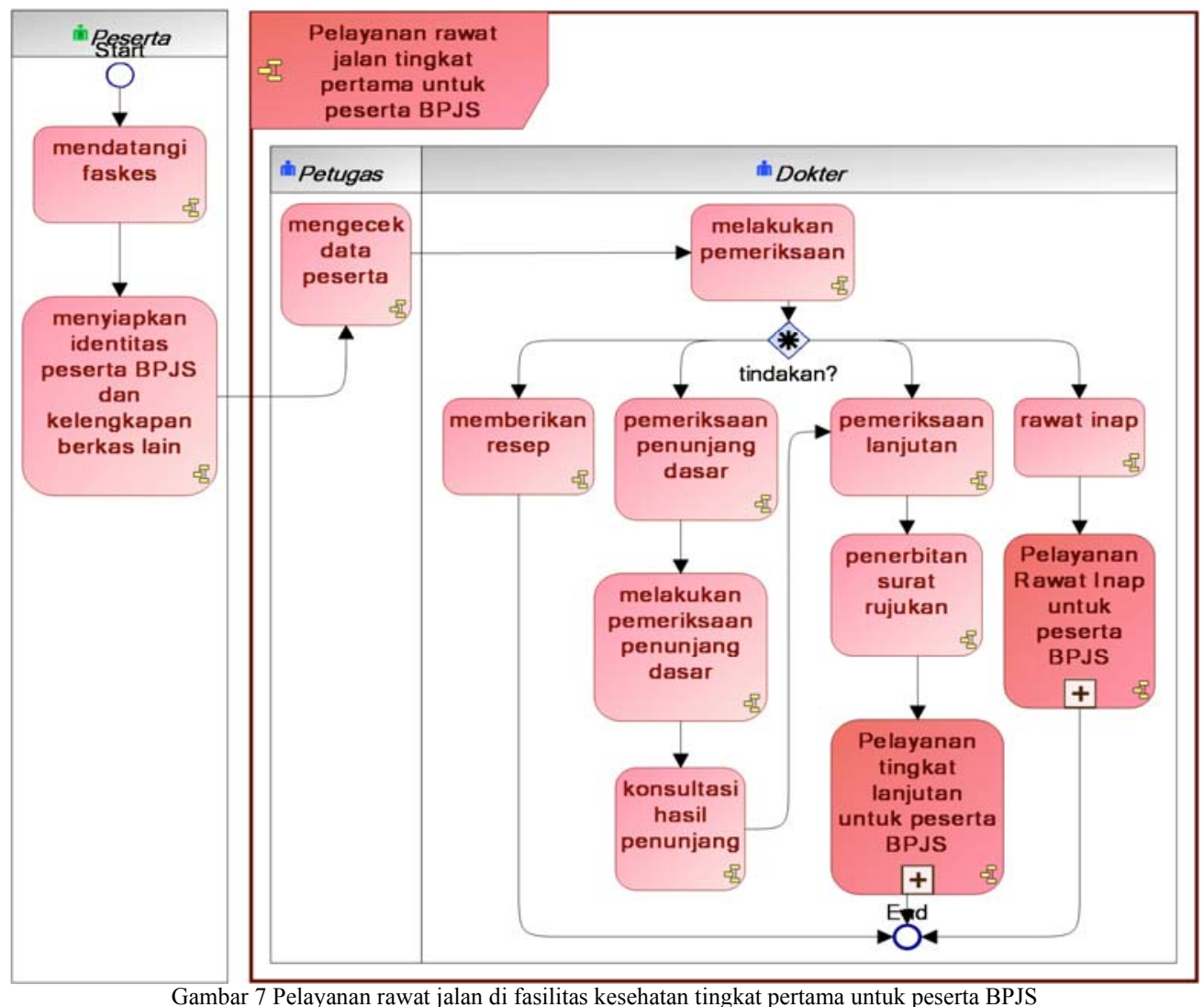

Gambar 7 Pelayanan rawat jalan di fasilitas kesehatan tingkat pertama untuk peserta BPJS

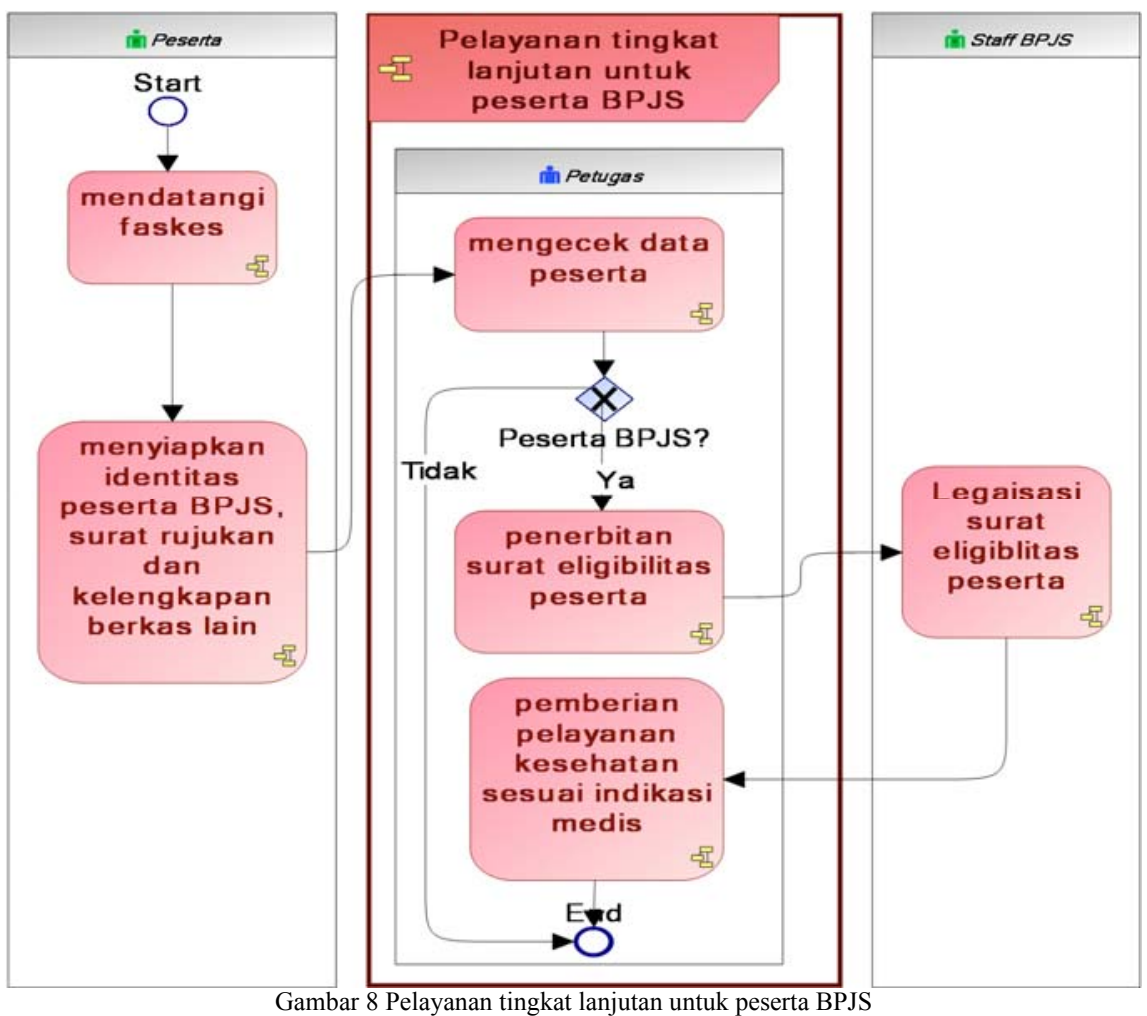

Perancangan dan Analisis Enterprise Architecture PT. XYZ pada Domain Arsitektur Bisnis dengan Menggunakan Framework TOGAF ADM 


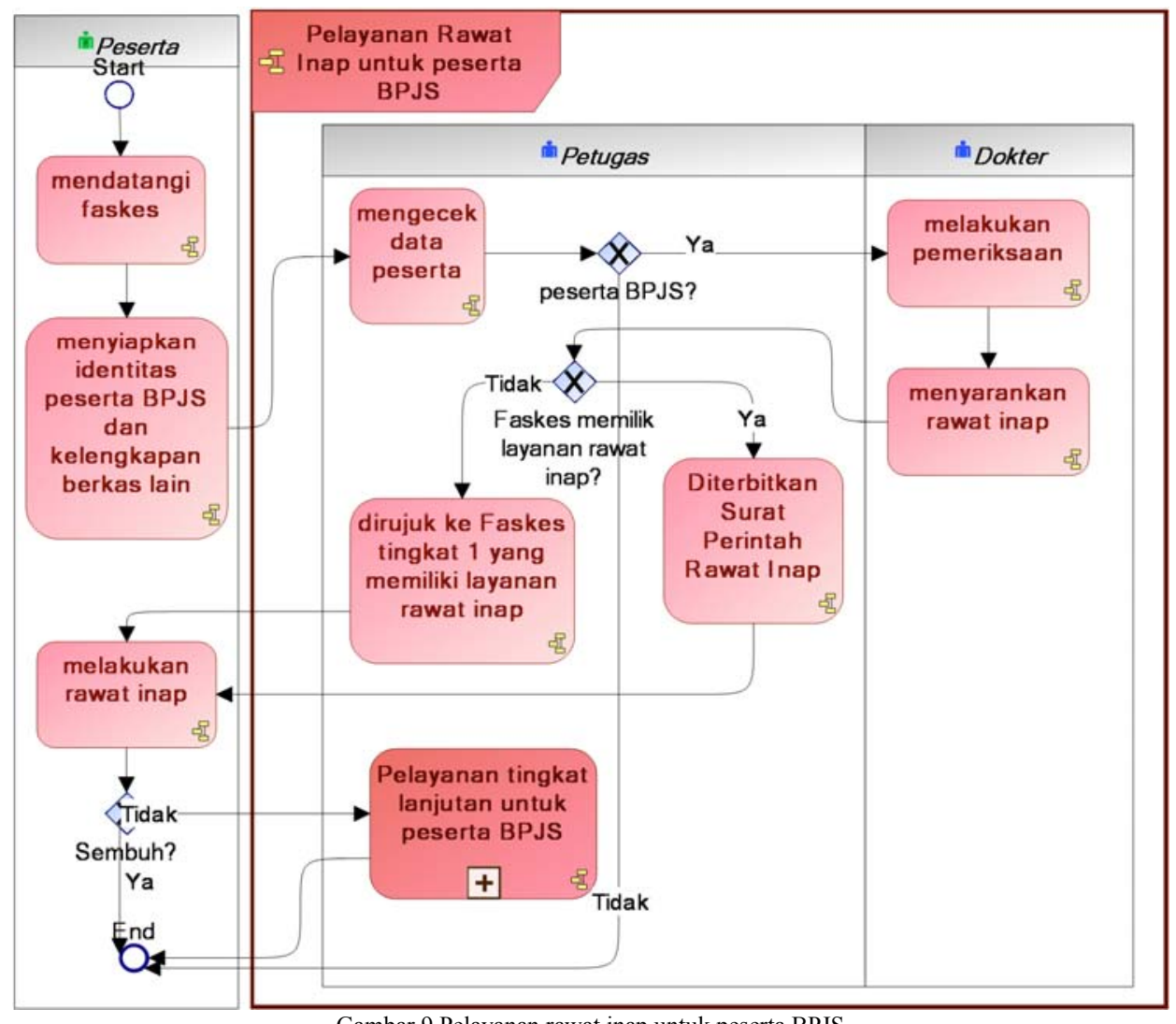

Gambar 9 Pelayanan rawat inap untuk peserta BPJS
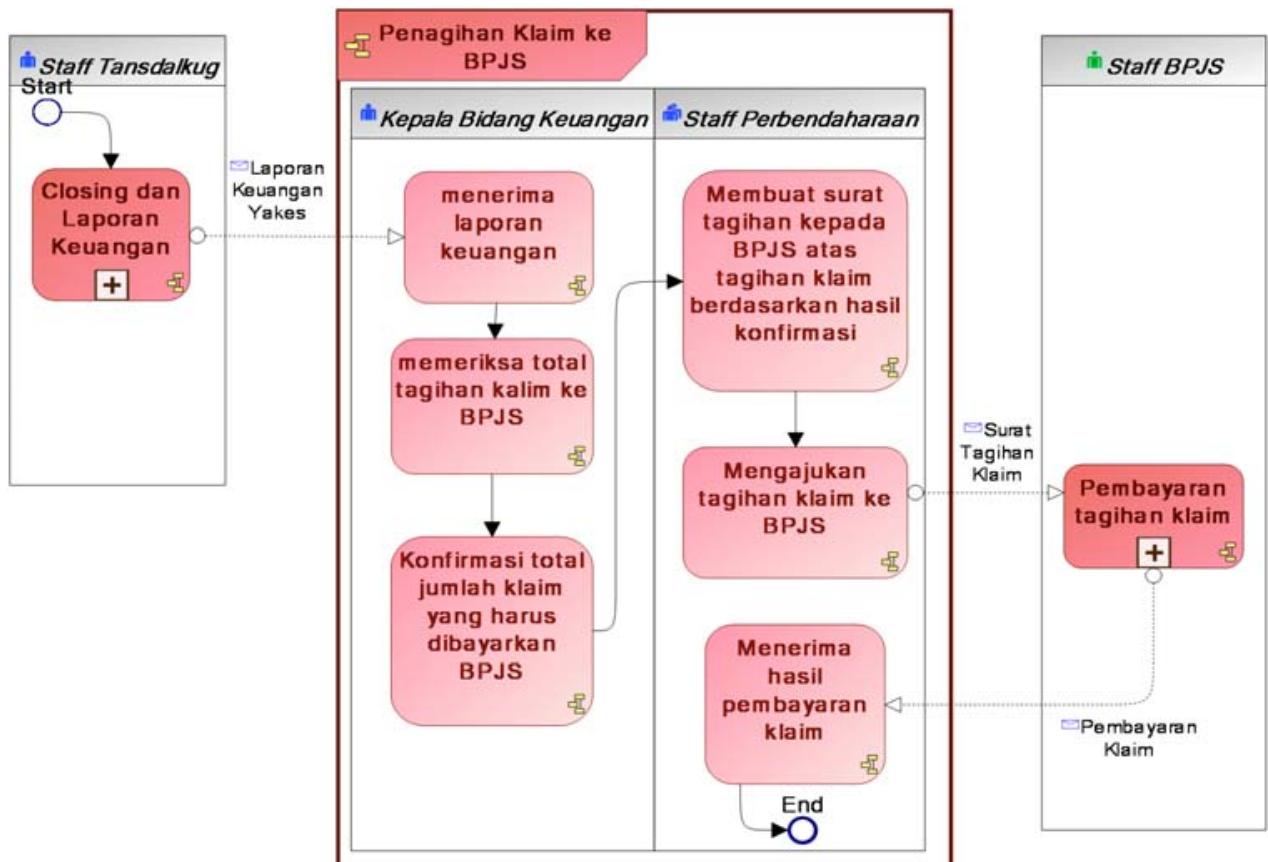

Gambar 10 Penagihan klaim ke BPJS Kesehatan 


\section{IV.KESIMPULAN DAN SARAN}

Berdasarkan hasil rancangan dan analisis bisnis yang telah dijelaskan, maka dapat disimpulkan keselarasan kerjasama antara PT. XYZ dan BPJS Kesehatan dapat terjadi dengan adanya penambahan stakeholder staf BPJS, dan juga perubahan dan penambahan proses bisnis serta data yang dihasilkan maupun digunakan. Perubahan proses bisnis yang dimaksud diantaranya pengajuan menjadi peserta baru PT. XYZ dan perubahan data peserta, dan penambahan proses bisnis yang ada diantaranya rawat jalan tingkat pertama untuk peserta BPJS, rawat jalan tingkat lanjut untuk peserta BPJS, rawat inap untuk peserta BPJS, peminjaman dan penjaminan ambulan, dan penagihan klaim.

\section{DAFTAR PUSTAKA}

[1] Republik Indonesia, Undang-Undang No. 24 Tahun 2011 tentang Badan Penyelenggara Jaminan Sosial (BPJS), Jakarta: Sekretariat Negara, 2011.

[2] Pusat Pendidikan dan Pelatihan Manajemen Rumah Sakit Indonesia, Tantangan Ganda Tahun 2015 bagi Praktisi Kesehatan Indonesia, no. BPJS, 2015.

[3] http://pubs.opengroup.org/architecture/togaf9doc/arch/chap02.html, diakses November 2014.

[3] PT. XYZ, Rencana Kerja Manajerial, Bandung, 2012.

[4] J. Ward and J. Peppard, Strategic Planning for Information System, United Kingdom: John Wiley \& Sons, LTD, 2002.

[5] The Open Group, Sample Catalogs, Matrices, and Diagrams, 2011. 